\title{
Physicians' Internet use: diffusion through compatibility and observability
}

\author{
F. Chew ${ }^{1} \&$ W. Grant ${ }^{2}$ \\ ${ }^{1}$ S.I. Newhouse School of Public Communications, \\ Syracuse University, USA \\ ${ }^{2}$ Department of Emergency Medicine, \\ SUNY Upstate Medical University, USA
}

\begin{abstract}
A national mail survey of 683 randomly selected US family physicians was conducted using diffusion of innovations theory to assess Internet use perceptions and identify sources from which physicians obtained medical information. Continuing medical education (CME), medical journals and professional colleagues were the top three sources of medical information. Internet use diffused through five starting points and three paths. They are 1) assessing the professional association website as helpful, 2) taking a CME course on Internet navigation or participating in an Internet demonstration, 3) having a teaching hospital affiliation, 4) a lower patient load and 5) recent professional training (within the past 10 years). From here the three pathways included observing its benefits, utilization compatibility and ease, and getting useful information. Continuing medical education with an emphasis on demonstration constitutes the optimal means for socializing family physicians to learn how to navigate the Internet.
\end{abstract}

Keywords: Internet use, family physicians, diffusion.

\section{Introduction}

Family medicine has increasingly become an information-intensive specialty reliant on relevant original research published in many multidisciplinary and subspecialty journals [1]. Therefore, practitioners must be knowledgeable about the best evidence for clinical practice from disease screening to bioterrorism threat response and assisting patients to assess Internet health information. More 
are integrating Internet communications in their medical practice as new online evidence-based scientific studies become accessible, patients request web health information sources and online communications and navigation improve [1,2].

Even with explosive growth in the field and a geometrically increasing number of users, the use of technology in health care remains behind that found in other industries [3]. This continues in spite of pressures such as the need to respond to the shifts in standards of care moving from the "locality" rule to a demand that physicians have a duty to stay current with national developments in their field using a variety of sources [4].

Consequently, the need to master technology as an information management tool is significant because it influences the way family physicians practice, research, teach and learn [5]. The American Medical Association's 2001 Internet survey among physicians reported that 78 percent used the Internet [6]. No specific data are available for family physicians. The present study applied the diffusion of innovations theory [7] to examine how family physicians currently perceive and use the Internet in their medical practice in order to develop strategies for increasing and systematizing its usage.

Diffusion of innovations theory describes how an innovation spreads over time through specific channels among members of a social system." [7] Five innovation attributes contribute to its rate of adoption: relative advantage (improvement over the idea it replaces), compatibility (fit with adopters' existing values and needs), complexity (ease of use and understanding), trialability (ability to be experimented with), and observability (visible results) [7]. More readily accepted innovations have higher relative advantage, compatibility, trialability, observability, and less complexity.

Previous research showed that family physicians recognized the Web's utility [8] and desired quick, accessible and trustworthy information [9] yet many were unaware of peer-reviewed research evidence [10] and found point-of-searching time-inefficient [11]. In addition, family physicians spent more time on patient care and had little time for online searches compared with other subspecialty physicians [12]. Training recency was found to influence Internet use [13] as was younger age [14] and male gender [15]. Likewise, Internet perceptions were influenced by recency and female gender [16]. The present study was guided by the question - What is the optimal approach for promoting Internet use among family physicians?

\section{Method}

A mail survey was conducted among 2000 family physicians drawn from the national directory of family physicians maintained by the American Academy of Family Physicians (AAFP). From April 15 through August 19, 2004, three waves of mailings were fielded using a stratified random sampling of family physicians by states. As a validation procedure, a weighted sampling technique [17] was applied to reflect the differences in the original sampling planning and the response distribution. 
Questions focused on Internet access, use and interest in computers at work and at home, sources of information, best communication approaches and Internet perceptions specifically its innovation attributes of relative advantage, compatibility, observability, trialability and complexity. Perception measurement items were developed from previous medical information technology adoption research [13-16, 18-20] and were operationalized with two statements per attribute (Table 1) using a 5-point Likert scale. The items were scored, summed and averaged for each attribute.

A professional Internet use index was created by coding and summing positive responses to five questions: 1) Internet use at work, 2) getting email from patients, 2) replying to patient email, 3) emailing medical information to patients, and 3) giving email the highest priority for receiving bioterrorism alerts. Cronbach's alpha was 0.70 .

Statistical analyses included frequencies, Spearman's correlations, and regression analysis. Probability acceptance levels were set a priori at $p<.05$.

\section{Results}

A total of 683 respondents completed the survey (response rate of $34.3 \%$ ) and comprised $65.9 \%$ male and $34.1 \%$ female. Averaging 46.2 years of age, the sample's demographic profile showed that more than a third $(35.1 \%)$ had affiliations with a major teaching hospital. Most (60.9\%) earned their professional degrees more than 10 years ago with about a fifth (18.9\%) becoming credentialed professionally 5 to 10 years ago or in the past five years $(20.2 \%)$. Consequently, nearly two in five $(39.2 \%)$ obtained their professional training during the early Internet years of the 1990s. On the question of patient load, overall they averaged seeing 23.7 patients a day.

Technological connectivity. Nearly all $(94.9 \%)$ the family physicians had computers at their place of work and most $(86.5 \%)$ did use them here. Most (91\%) had Internet access at work and nearly all (95.3\%) reported having Internet access at home. Overall, family physicians averaged 6.9 years of computer use with a range of two weeks to 25 years.

Patient Communication. On the topic of using Internet technology to communicate with patients, about a fifth $(21.6 \%)$ indicated receiving patient email, one in six $(17 \%)$ emailed in reply, and nearly a tenth $(9.3 \%)$ emailed important medical information to patients.

Sources of communication. Family physicians considered continuing medical information (CME) the most helpful source of information to keep them updated in their medical practice $(\underline{\mathrm{M}}=4.25, \mathrm{SD}=0.76)$. Second on the list was medical journals $(\underline{\mathrm{M}}=3.96, \mathrm{SD}=0.91)$, followed by professional colleagues $(\underline{\mathrm{M}}=3.80$, $\mathrm{SD}=0.95)$, and the American Academy of Family Physicians website $(\underline{\mathrm{M}}=3.06$, $\mathrm{SD}=1.53)$. The best communication method for obtaining bioterrorism alerts was email (48.4\%). Other frequently selected methods included fax (33.2\%), express mail (20.6\%) and the AAFP website (15.2\%).

Information technology perceptions. Nearly all could type and therefore use the computer (91.2\%). About half had time to browse the Internet (50.6\%) and had 
excellent Internet skills (48.0\%), and two in five $(38.7 \%)$ would take a CME course on Internet navigation. A plurality of family physicians agreed and strongly agreed with the following Internet attribute items - it had observable benefits (78.9\%), its use had advantages (63-66\%), it did not take too much effort $(61.6 \%)$, and its potential to improve work was demonstrable (55.1\%). See Table 1 . The moderate to strong statistically significant correlations $(r=0.25$ to $0.61, p<.001$ ) for the five innovation attributes support their construct validity.

Table 1: Internet technology perceptions among US family physicians $(n=683)$.

\begin{tabular}{|c|c|c|}
\hline Innovation Attributes & $\begin{array}{l}\text { Percent Agree } \\
\text { and Strongly } \\
\text { Agree }\end{array}$ & Mean (SD) \\
\hline $\begin{array}{l}\text { Relative Advantage } \boldsymbol{r}=\mathbf{. 6 1 1} * * \\
\text { Specific Internet sites are a treasure trove } \\
\text { I get a lot of useful information from the } \\
\text { Internet }\end{array}$ & $\begin{array}{l}63.0 \\
66.0\end{array}$ & $\begin{array}{l}3.60(1.14) \\
3.67(1.07)\end{array}$ \\
\hline $\begin{array}{l}\text { Compatibility } \boldsymbol{r = . 5 6 1 * *} \\
\text { "Searching the Internet takes too much } \\
\text { effort } \\
\text { "I don't have time to browse the Internet }\end{array}$ & $\begin{array}{l}61.6 \\
50.6 \\
\end{array}$ & $\begin{array}{l}3.60(1.17) \\
3.24(1.32) \\
\end{array}$ \\
\hline $\begin{array}{l}\text { Lack of complexity } \mathbf{r}=\mathbf{. 2 4 9 * *} \\
{ }^{\star} \text { I don't type so I don't use the computer } \\
\text { My Internet skills are excellent }\end{array}$ & $\begin{array}{l}91.2 \\
48.0 \\
\end{array}$ & $\begin{array}{l}4.51(0.93) \\
3.42(1.12)\end{array}$ \\
\hline $\begin{array}{l}\text { Observability } r=\mathbf{3 6 0} * * \\
\text { Some of my colleagues have benefited } \\
\text { from Internet use } \\
\text { Using the Internet has improved clinical } \\
\text { practice }\end{array}$ & $\begin{array}{l}78.9 \\
59.9\end{array}$ & $\begin{array}{l}3.71(1.31) \\
3.52(1.11)\end{array}$ \\
\hline $\begin{array}{l}\text { Trialability } r=.417 * * \\
\text { I'd like to see how the Internet can } \\
\text { improve my work } \\
\text { I would take a CME course on Internet } \\
\text { navigation }\end{array}$ & $\begin{array}{l}55.7 \\
38.7\end{array}$ & $\begin{array}{l}3.43(1.10) \\
2.91(1.26)\end{array}$ \\
\hline
\end{tabular}

Reverse coded; ${ }^{*} p<.001$; Spearman correlations $(r)$ were computed between the paired innovation attributes.

Subjects were asked to rate the above statements on a 5-point Likert scale ( $1=$ strongly disagree, $5=$ strongly agree); $\mathrm{SD}-$ standard deviation.

Promoting Internet Use. Through regression analyses, five starting points and three paths were found to promote Internet use. Table 2 reports the results of five regression equations predicting Internet use, relative advantage, lack of complexity, obervability and compatibility. Also listed for each of the final equations are the semi-partial correlation $\left(s r^{2}\right)$ or unique proportion of variance explained by a specific independent variable, its standardized beta weight (Beta), the correlation $(r)$, and variance $\left(R^{2}\right)$. Figure 1 profiles the linkages. 
Table 2: Hierarchical regression coefficients predicting Internet usage and innovation attributes $(n=683)$.

\begin{tabular}{|c|c|c|c|}
\hline Predictor Variables & $s r^{2}$ & Beta & $p$ \\
\hline & \multicolumn{3}{|c|}{ Internet Usage } \\
\hline Relative advantage & .06 & .17 & .001 \\
\hline Teaching hospital affiliation & .03 & -.13 & .01 \\
\hline Number of daily patients & .02 & -.13 & .01 \\
\hline Year completed professional training & .02 & .14 & .001 \\
\hline Lack of complexity & .01 & .13 & .05 \\
\hline$R^{2}$ & .115 & & \\
\hline \multirow[t]{2}{*}{$r$} & $.35 * * *$ & & \\
\hline & \multicolumn{3}{|c|}{ Relative advantage } \\
\hline Observability & .34 & .43 & .001 \\
\hline Compatibility & .10 & .25 & .001 \\
\hline Lack of complexity & .03 & .22 & .001 \\
\hline Trialability & .01 & .08 & .05 \\
\hline$R^{2}$ & .47 & & \\
\hline \multirow[t]{2}{*}{$r$} & $.69 * * *$ & & \\
\hline & \multicolumn{3}{|c|}{ Lack of complexity } \\
\hline Compatibility & .29 & .45 & .001 \\
\hline Trialability & .02 & -.16 & .001 \\
\hline Observability & .02 & .13 & .001 \\
\hline Year completed professional training & .01 & -.11 & .01 \\
\hline$R^{2}$ & .33 & .45 & .001 \\
\hline \multirow[t]{2}{*}{$r$} & $.58 * * *$ & & \\
\hline & \multicolumn{3}{|c|}{ Observability } \\
\hline Compatibility & .12 & .33 & .001 \\
\hline AAFP website & .04 & .19 & .001 \\
\hline Teaching hospital affiliation & .02 & -.16 & .001 \\
\hline Trialability & .02 & .14 & .001 \\
\hline$R^{2}$ & .20 & & \\
\hline \multirow[t]{2}{*}{$r$} & $.45 * * *$ & & \\
\hline & \multicolumn{3}{|c|}{ Compatibility } \\
\hline AAFP website & .03 & .19 & .001 \\
\hline Trialability & .03 & -.16 & .001 \\
\hline Number of daily patients & .01 & -.10 & .05 \\
\hline$R^{2}$ & .07 & & \\
\hline$r$ & $.26 * * *$ & & \\
\hline
\end{tabular}

$* * * p<.001$. 


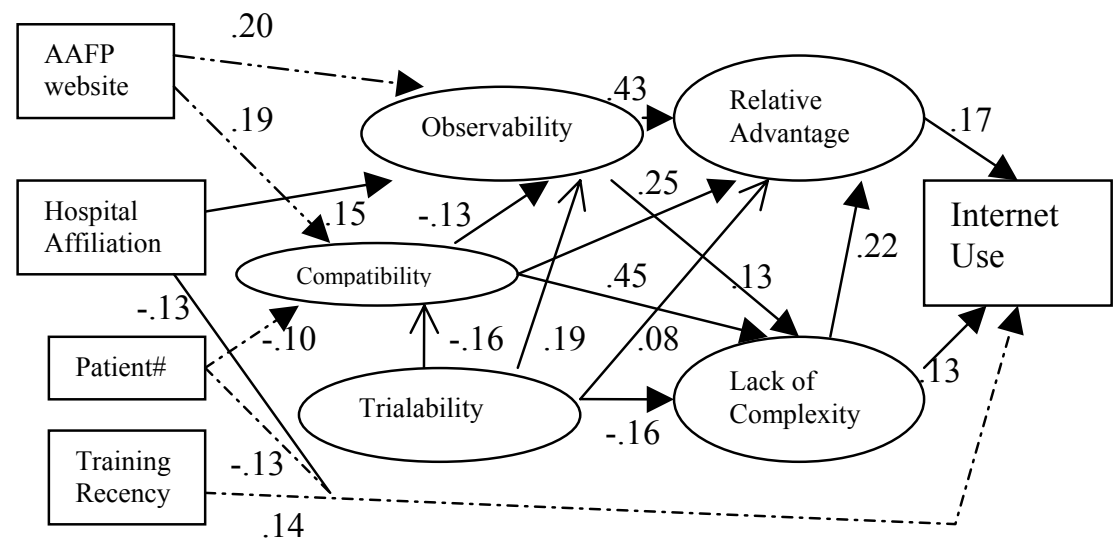

\#Betas

Figure 1: Predictors\# of Internet use and innovation attributes (relative advantage, lack of complexity, observability and compatibility).

\section{Discussion and conclusion}

The five starting points are 1) rating the AAFP website to be helpful, 2) trialability (deciding to take an CME course on Internet navigation or trying it out through a demonstration), 3) having a teaching hospital affiliation, 4) a lower patient load and 5) recent professional training (within the past 10 years). The three paths are via relative advantage, observability and low complexity and these are also related to the other diffusion of innovation attributes.

The first path begins when family physicians assess the AAFP website as a helpful source of updated medical information. They are able to observe their colleagues benefiting from Internet use (observability) and at this point, and are able to check out websites which are a clinician's "treasure trove" and obtain useful information from the Internet (relative advantage) which leads them to use the Internet professionally. Observation of their colleagues results in their reassessing their own Internet and typing skills as facile (lack of complexity), and in turn lead them to use the Internet to respond to patients and as the means of getting bioterrorism alerts.

A second direction after considering the AAFP website helpful would be to assess Internet searches as less of an effort and taking less time (compatibility). Physicians would then be more predisposed to observe their colleagues benefit from Internet use (observability) and consider it a source of useful and plentiful information (relative advantage) or as a convenient means to obtain information.

Another diffusion of innovation starting point is when physicians decide to take a CME course on Internet navigation or try it out through a demonstration 
(trialability). From here, they can either move towards considering Internet use compatible, observing its benefits, perceiving it as easy to use (low complexity) or a treasure trove (relative advantage).

Three other starting points include a teaching hospital affiliation, having a lower number of daily patients which gives them more time and having completed their professional training within the past ten years. These directly influence Internet use.

Previous research supports the inverse relationship of patient load to Internet use [12]. Through systematic practice, the family physician's Internet skills will improve sufficiently to start benefiting from accessing evidence-based medical/clinical research via web-based sources. Consequently, the first step in the second path to Internet use which involves taking a CME course on Internet navigation and getting an Internet use demonstration is a logical one. Once some practical experience is obtained, Internet skills should improve to a level that it takes less no time or effort (compatibility). The subsequent step focuses on observing colleagues benefiting from Internet use and getting helpful information on the Internet for clinical practice. Optimally occurring after work hours these activities will improve basic Internet navigation skills to further enhance the family physician's information retrieval for clinical practice. Training recency boosted Internet use because during the training, Internet use was most likely part of the curriculum. Similarly, having a teaching hospital affiliation sensitized physicians to the need for integrating IT to manage information in their medical practice.

In this study, continuing medical education (CME) constitutes the optimal means for family physicians to learn how to navigate the Internet. If courses are offered in a short specific time frame and integrated into physicians' intensive schedules, these would be feasible options. Basic technical skills need to be in place, before it is possible to build more advanced information technology skills.

Future research should examine the nature of the social system, the time taken for the diffusion of IT, innovation dynamics such as the use of innovation incentives, characteristics of the agents of change/opinion leaders and the relationship between voluntary versus system-mandated innovation adoption. Technology and information management are part of family medicine and medical schools have incorporated them as essential parts of the curricula. Critical skills include identifying the most useful clinical information through information management mastery. Next, evaluation skills to critique and appraise medical evidence are important followed by computer and Internet usage skills. The Internet has the potential to improve the quality of medical practice and patient care. All it takes is knowing how to utilize it.

\section{References}

[1] Ebell MH, Frame P. What can technology do to, and for, family medicine. Fam Med 2001:33(4):311-9. 
[2] Diaz JA, Griffith RA, Ng JJ, Reinert SE, Friedmann PD, Moulton AW. Patients' use of the Internet for medical information. J Gen Intern Med 2002; 17(3):180-5.

[3] Landro L. What's ahead for Health Care: Information Technology Could Revolutionize the Practice of Medicine; But Not Anytime Soon. Wall St. J. June 25, 2001 at R14.

[4] Sokol AJ Molzen CJ. The changing standard of care in medicine: EHealth, medical errors and technology add new obstacles. J. Legal Med. 2002;23:449-490.

[5] Crandall S, Elson R, McLaughlin C. Managing and communicating information in a new era. Fam Med 1997:29(4):270-4.

[6] American Medical Association. AMA study: Physicians' use of Internet steadily rising. News release. July 17, 2002. http://www.amaassn.org/ama/pub/print/article/1616-6473.html. Site visited April 1, 2003.

[7] Rogers E. Diffusion of Innovations. $4^{\text {th }}$ Edition. New York: Free Press. 1995.

[8] Tuominen K, Crouse BJ. Use of the World Wide Web by family practitioners. Minn Med 1996:79(11):43-6.

[9] Feighter JW, Marshall JN, Sangster LM, Wathen CN, Quintana Y. Evidence-based preventive practice guidelines. Qualitative study of useful resources on the Internet. Can Fam Physician 2001:47:1577-83.

[10] Sigouin C, Jadad AR. Awareness of sources of peer-reviewed research evidence on the Internet. JAMA 2002:287(21):2867-9.

[11] Alper BS, Stevermer JJ, White DS, Ewigman BG. Answering family physicians' clinical questions using electronic medical databases. J Fam Pract 2001:50(11):960-5.

[12] Marshall JG. Characteristics of early adopters of end-user online searching in the health professions. Bull Med Libr Assoc 1989:77(1):4855.

[13] Jerant AF, Lloyd AJ. Applied medical informatics and computing skills of students, residents and faculty. Family Medicine 2000:32(4):267-72.

[14] Clayton PD, Pulver GE, Hill CL. Physician use of computers: Is age or value the predominant factor? AMIA 1989; 301-5.

[15] Eitel ER, Yankowitz J, Ely JW. Use of Internet technology by obstetricians and family physicians. JAMA 1998; 280(15): 1305-6.

[16] Chew F, Grant W, Tote R. Doctors online: Using diffusion of innovations theory to understand Internet use. Fam Med 2004: 36(9), 567-572.

[17] Gelman A, Carlin JB. (2001). Postratification and weighting adjustments. In Survey Nonresponse, ed. RM Groves, DA Dillman, JL Eltinge, RJA Little. New York: Wiley.

[18] Dixon DR, Stewart M. Exploring information technology adoption by family physicians: survey instrument valuation. PROC American Medical Informatics Association Annual Symposium 2000; 185-9.

[19] Ash JS, Lyman J, Carpenter J, Fournier L. A diffusion of innovations model of physician order entry. PROC AMIA 2001; 22-26. 
Data Mining VIII: Data, Text and Web Mining and their Business Applications 253

[20] Versweyveld, L. What influences physicians to adopt medical innovations, such as telemedicine. Virtual Medical Worlds, 1999. Retrieved 5/11/2003 from http://www.hoise.com/vmw/99/articles/vmu/ LV-VM-05-99-12.html

[21] Helitzer D, Maltrud K, Heath D, Sullivan E, lverson D. Assessing or predicting adoption of telehealth using the diffusion of innovations theory: A practical example from a rural program in New Mexico. Telemedicine Journal and e-Health 2003; 9(2): 179-187. 